\title{
Postverbal argument order in Yucatec Maya
}

\begin{abstract}
This paper presents experimental data on postverbal argument order in Yucatec Maya. Yucatec Maya is a verb initial language which according to previous analyses displays verb-agent-patient as its canonical order. The data presented in this paper were obtained in an experiment on interpreting ambiguous sentences. The experiment evaluated hypotheses about the impact of animacy, definiteness, verbal aspect and pragmatic preferences on Yucatec Mayan postverbal orders. The participants of the experiment showed considerable instability in role choice for postverbal arguments, sometimes preferring the agent-patient and sometimes the patient-agent order. The role choice is predominantly determined by pragmatic inferences which are supported by inherent properties of the postverbal NPs like animacy and definiteness.
\end{abstract}

\section{Preliminaries ${ }^{1}$}

Mayan languages are almost exclusively verb-initial, divided into two subgroups according to their argument order preferences, namely those that favor verb-patient-agent and those that favor verb-agent-patient as the canonical order. Yucatec Maya has always been considered a verb-patient-agent language, the verb-agent-patient order being marginal or of unclear grammaticality status (see Durbin \& OJEDA 1978: 70; England 1991: 460). A closer inspection of data from text corpora shows that both orders are attested.

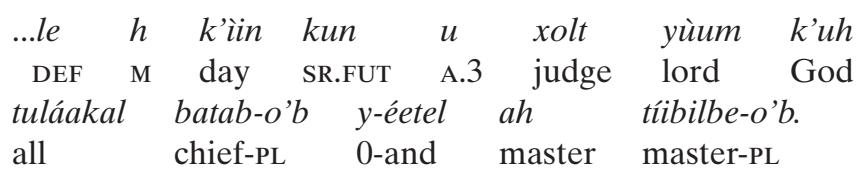

'(...) that will be the day on which Yum K'u is going to judge all chiefs and masters.'

[Hapaikan 41.3-4]

1 We wish to thank Gisbert Fanselow who supported us with valuable comments throughout the investigation, from the design of the experiment to the interpretation of the data. Grateful thanks are also due to Christian Lehmann, Christel Stolz, Thomas Stolz, Angeliki Ralli, Alkistis Skopetea, and Elizabeth Medvedovsky for helpful comments on various aspects of the investigation. We also want to thank the linguistic audiences at the Universities of Patras and Bremen for commenting on presentations of this paper. The empirical study on Yucatec Maya as well as the field work were supported by research center 632 "information structure" at the University of Potsdam for Stavros Skopeteas and by the University of Erfurt for Elisabeth Verhoeven. 


\begin{tabular}{|c|c|c|c|c|}
\hline$K-u$ & pakt-ik & bin & le & sáastun \\
\hline IPFV-A.3 & look-INCMPL(B.3) & QUOT & DEF & light:stone \\
\hline $\begin{array}{ll}l e & \text { c } \\
\mathrm{DFF} & \mathrm{l}\end{array}$ & $\begin{array}{l}\text { xibpal-e' } \\
\text { man:child-I }\end{array}$ & & & \\
\hline
\end{tabular}

'The little boy looked at the crystal ball; (...).'

[Hk'an 123.1]

The aim of this paper is to investigate the argument order preferences in Yucatec Maya on the basis of experimental evidence. It is known from studies on several Mayan languages that postverbal orders in this family are often influenced by inherent properties of the NP arguments, notably animacy and definiteness. Both categories have an impact on the choice of syntactic function and/or on the choice of order in language production, following universal preferences such as the tendency to place given information at the beginning of the clause, or the tendency for animacy properties to be harmonically coupled with thematic roles (animate agent and inanimate patient are favored). The experimental data of this paper will be tested on the basis of these cross-linguistic preferences. Two typological properties of Yucatec Maya are of particular interest in word order studies and will be discussed in length with respect to the experimental data: the first is the interaction between head-marking morphology and word order and the second is the particularity of the verb-patient-agent order.

Most studies on Mayan argument order classify languages in terms of VOS and VSO orders, although it is not clear what is the cross-linguistic concept of "subject" and "object" in a language family with such different alignment systems as ergative (e.g. Quiché, Acatec, Mamean languages, etc.), active/stative (Mopan, cf. DANZIGER 1996), split ergative (e.g. Mocho $^{2}$, cf. England \& MarTin 2003: 132), split intransitive (Yucatec Maya ${ }^{3}$, cf. section 2.2.), etc. In order to avoid this methodological difficulty and keeping in line with the general skepticism in diverse studies on comparative syntax concerning the question whether "subject" is an adequate universal concept (cf. DiXon 1979; DrYer 1997; FANSELOW 2002; VAN VAlin \& LAPOLLA 1997, ch. 6), in this paper we will adopt the use of thematic roles rather than syntactic functions. Furthermore, since our experimental data contains interpretations of clauses, it provides direct evidence for the role choices preferred in different contexts and only indirect evidence for the choice of syntactic function. Hence, the argument orders that are discussed in this paper are verb-patient-agent (henceforth VPA) and verb-agent-patient (henceforth VAP), and these terms will be unambiguous in the context of this paper, given that we always deal with active clauses. ${ }^{4}$

The structure of the paper proceeds as follows: In section 2, we will give some background information, first about argument orders in Mayan languages (section 2.1.) and then about the major grammatical traits of Yucatec Maya with special emphasis on those that may have an impact on word order (section 2.2.). In section 3, we present the design of our experimental study, and in section 4 we discuss the data obtained with relation to several assumptions about argument orders from previous studies on word order. The experimental generalizations will be compared with naturalistic data from spontaneous

2 Mocho maintains ergative marking for third person, having shifted to accusative marking for first/ second person.

3 For an investigation of the organization of syntactic functions in Yucatec Maya cf. VerHoEven 2005, ch. 4.3. Applying typologically valid syntactic tests, Yucatec Maya can be argued to display a rather weekly implemented accusatively aligned subject.

4 "Agent" and "patient" are used here in the sense of proto-roles (see "actor" and "undergoer" in vaN VALIN \& LAPolla 1997 or "proto-agent" and "proto-patient" in DowTY 1991). 
speech in section 5. The final section summarizes the results and gives a general outline of the resulting implications for the grammar of Yucatec Maya.

\section{Language and family profile}

\subsection{Canonical argument order in Mayan languages}

Canonical constituent order varies across different Mayan languages. The Greater Mamean languages (cf. England 1989: 287 for Mam, England 1991: $451 \mathrm{ff}$. for Mam, Tectiteco, Aguacatec, Ayres 1983: 21 for Ixil) and some of the Kanjobalan-Chujean languages (cf. e.g. Grinevald Craig 1977: 8 for Jacaltec, England 1991 for Kanjobal) are reported to have rigid VAP as the canonical order. In contrast, the Tzeltalan languages (cf. Aissen 1987 for Tzotzil, Robinson 2002 for Tenejapan Tzeltal) and the Yucatecan languages (cf. Hofling 1984, Durbin \& OJeda 1978 for Yucatec Maya) as well as Tzutujil (cf. Dayley 1985, Duncan 2003), Kekchi (cf. Tzul \& Tzimaj Cacao 1997), Pocomam (cf. SAntos Nicolas et al. 1997), and Tojolabal (cf. Brody 1982) are analyzed as displaying VPA as canonical order. In most languages of this latter group, canonical VPA competes with AVP, according to England (1991). Furthermore, a number of Mayan languages are analyzed as displaying two canonical orders, VPA and VAP, namely Huastec (NormAn \& Campbell 1978), the Kanjobalan languages Acatec ${ }^{5}$ (Peñalosa 1987: 283) and Mocho (ENGLAND 1991), as well as the Quichean languages Kaqchikel (cf. e.g. BroAdwell i.p.: 16) and Quiché (cf. e.g. MondLoch 1981). Finally, Chorti is the only Mayan language which has been analyzed as basically AVP as a result of a recent development, possibly based on contact with the superstratum Spanish (ENGLAND 1991 based on QuIZAR 1979). In general, it is held for most Mayan languages (presumably with the only exception being Chorti) that the postverbal orders are the pragmatically neutral ones. Preverbal realization of A or $\mathrm{P}$ is pragmatically marked, resulting in topic and focus meanings, and in many languages it is also structurally marked, as will be shown for Yucatec Maya in section 2.2.

The following family tree of the Mayan languages (adapted from the current Ethnologue version) indicates the canonical orders given for Mayan languages according to the sources cited above (see Fig. 1).

As for the Proto-Mayan canonical order, Norman \& CAmpbell (1978: 146) assume that it was flexible VPA/VAP, the actual order being conditioned by the relative position of $\mathrm{A}$ and $\mathrm{P}$ on the animacy hierarchy (VAP if $\mathrm{A}=\mathrm{P}$ with respect to the animacy hierarchy and VPA if $A>P$ ). Their argument is based on data from flexible VPA/VAP Mayan languages, and notably from Tenejapan Tzeltal and Huastec. However, the former language is convincingly shown to display canonical VPA order instead of flexible VPA/VAP order by RoBinson (2002). ENGLAND (1991) reconstructs the Proto-Mayan canonical order as VPA, arguing that VAP is secondary and can be plausibly derived from VPA under certain conditions, but not vice-versa.

In languages that allow for both orders in the postverbal positions, a conditioning factor which is often cited is the relative position of the arguments in the animacy hierarchy. Next to animacy, other parameters as e.g. definiteness, weight, and pragmatic plausibility have been shown as decisive in accounting for a given postverbal argument order, too (cf. e.g. ENGLAND 1991, section 3.3, Aissen 1992).

5 Note however that ZavaLA (1997: 447f.) reports canonical VAP for Acatec. 


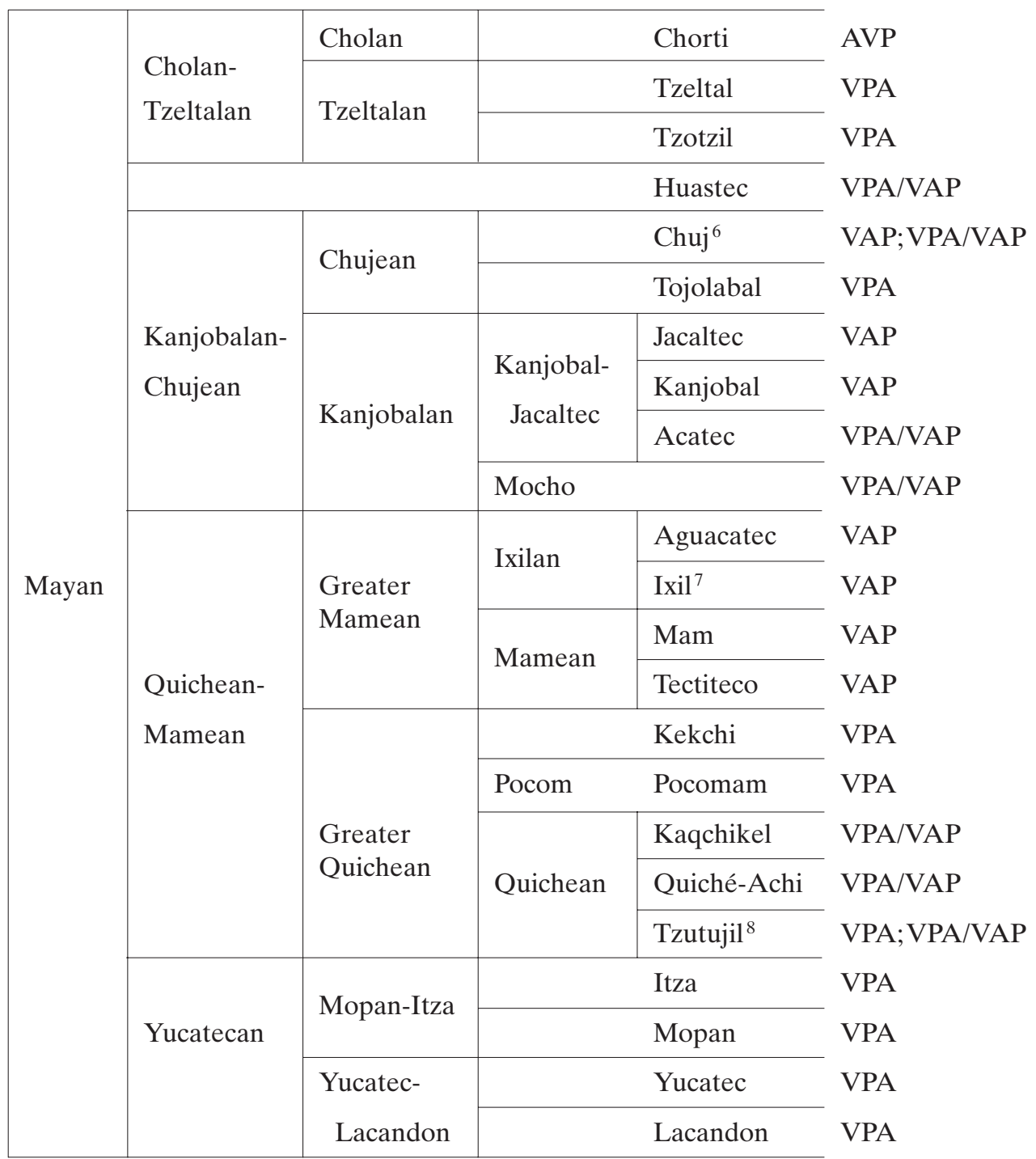

Fig. 1: Canonical word order in Mayan languages

6 The dialects of Chuj vary in canonical word order. EngLand (1991) identifies the dialect of San Sebastián as basic VAP while the dialect of San Mateo displays mixed VPA/VAP.

7 This holds according to England (1991) for the dialects of Nebaj and Chajul while the dialect of Cotzal is reported to display basic VPA.

8 Tzutujil also displays dialectal variation concerning basic word order, namely the dialects of San Juan and Santiago show canonical VPA (cf. DAYLEY 1985), while the dialect of San Pedro is said to have mixed VPA/VAP (ENGLAND 1991: $470 \mathrm{ff}$;; DunCan 2003: 166ff.). 


\subsection{Principal characteristics of Yucatec Maya}

Before we introduce the experimental goals and methodology of our study, we will provide a short outline of those properties of Yucatec Maya which are crucial for the analysis of the experimental data in section 4. Like all Mayan languages, Yucatec Maya is a head-marking language, i.e. the head is marked for the dependent(s) by cross-reference indices (see e.g. Lehmann 1991, 1998). Thus, the verb, the possessed noun, and the preposition are marked for their dependents [see (3)]. The cross-reference markers are indicated as A and B, referring to two series of markers. The so-called set-A clitics refer to the agent of a transitive verb, and the so-called set-B suffixes refer to the patient of a transitive verb (3a). Furthermore, the possessed noun is marked for the possessor by means of the set-A clitic [ $u$ 'A.3' in (3b)]. And the same goes for the preposition with respect to its complement [ $u$ 'A.3' in (3c)]. The occurrence of set-A clitics and set-B suffixes does not directly correspond to grammatical relations, let alone thematic roles. The functions of the set-A clitic include marking the sole actant of intransitive clauses with incompletive status along with marking the agent of a transitive verb and the possessor in a possessed noun phrase. Along with marking the patient of a transitive verb, the set-B suffixes mark the sole actant in intransitive clauses with completive or subjunctive status. Morphologically we are thus dealing with a split intransitive system of argument marking, conditioned by overt aspect/mood marking (BOHNEMEYER 2004).

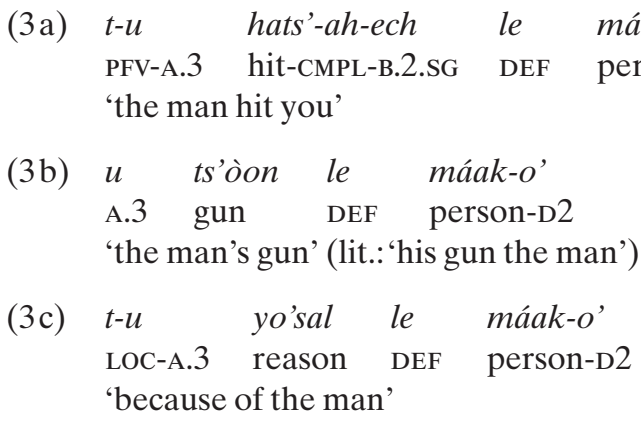

Furthermore, like in other head-marking languages (see e.g. vAN VALIN 1987), the heads in Yucatec Maya may stand alone, i.e. without overt realization of the dependents. E.g., the verb with its cross-reference markers may exhaust an independent clause and may constitute a complete utterance [cf. (4)].

$$
\begin{aligned}
& t \text { - } u \quad \text { hats'-ah-ech } \\
& \text { PFV-A.3 hit-CMPL-B.2.SG } \\
& \text { 'he/she/it hit you' }
\end{aligned}
$$

As has already been stated above, VPA is considered to be the canonical constituent order in Yucatec Maya (Durbin \& OJeda 1978, Hofling 1984). This holds on the basis of the criteria of morphological unmarkedness and pragmatic neutrality [see example (5) for an illustration of V-initial order in Yucatec Maya].

$\begin{array}{llll}T-u \quad \text { hàant-ah } & \text { òon } & \text { Pedro } . \\ \text { PFV-A.3 } & \text { eat:TrR-CMPL(в.3.SG) } & \text { avocado } & \text { Pedro } \\ \text { 'Pedro ate avocado.' } & & \end{array}$


The locus of relational information (head- vs. dependent-marking) also has an impact on the word order properties. First, it has been shown on the basis of statistical data from the world's languages that head-marking languages favor verb-initial orders (see NicHOLS 1986: 81, 104). The functional principle underlying this cross-linguistic generalization is based on processing ease: "give the relational information early in the clause". 9 Mayan languages support this cross-linguistic generalization, being consistently head-marking and predominantly verb initial (see Fig. 1).

Furthermore, head-marking languages are expected to exhibit more ordering freedom than dependent-marking languages (see STEELE 1978; Nichols 1986: 104; vAN VALIN 1987: 393). This typological expectation is opposed to the intuition that head-marking, especially in structures with more than one dependent, should result in more ambiguities than dependent-marking. In this latter view, word order is expected to have a compensatory role in functionally replacing the lack of morphological marking on arguments. However, head-marking and word order flexibility often correlate in language samples as a result of the low configurationality of this language type (see vaN VALIN 1987) and this view is supported by the Yucatec Mayan data of the present investigation.

Preverbal use of arguments is possible in Yucatec Maya, but it results in marked constructions. The preverbal orders are not simply linear alternatives to the postverbal ones, but bear special morphological markings encoding discourse functions of the anteposed elements. Hence, these orders may not qualify as canonical orders due to their structural complexity and pragmatic markedness (see Durbin \& OJEDA 1978). In the preverbal field, a topic and a focus position have to be distinguished. The topic position is clause initial, its right boundary is marked by the topic suffix $-e$ ', and it may be occupied by nouns, pronouns, adverbs, adjectives, and clauses (see BoHNEMEYER 1998b). Focus assignment is expressed through the displacement of an argument in the preverbal position, which in case of agent displacement also triggers a special verbal morphology. These argument focus constructions are analyzed as cleft sentences (see BRICKER 1979, BOHNEMEYER 1998a, ToNHAUSER 2003).

\section{Outline of the empirical study}

\subsection{Experimental goals}

The goal of this paper is to investigate empirically the postverbal orders in Yucatec Maya. Since the VPA VAP orders are considered possible in the previous literature, we have conducted an empirical study in order to find out which parameters condition the alternation in linear order. The parameters that will be investigated in our experiment are the following:

(a) ANIMACY: Animacy is assumed to be a central factor in determining postverbal argument orders in Mayan languages (see e.g. Norman \& CAMPbell 1978; England

9 There are several statistical generalizations supporting this principle: (a) SOV languages most often have case marking and no obligatory agreement (see Foster \& Hofling 1987: 477); (b) case is overwhelmingly present in OV languages and less likely to occur in VO languages (see FosTER \& HofLING 1987: 494); (c) agreement is the primary indicator of NP relations in S-final languages (Foster \& Hofling 1987: 475, KeEnan 1978); etc. 
1991; AISSEN 1992: 44). The general tendency is to harmonically couple the animacy hierarchy with the thematic role hierarchy, such that higher animates occupy the higher roles in the clause and vice versa.

(b) DEFINITENESS: Similar observations have been made with respect to definiteness, the preference here being for definite NPs to be interpreted as agents (see ENGLAND 1991).

(c) Verbal ASPECT: Verbal aspect plays a central role in Yucatec Mayan syntax. As already mentioned in section 2.2, it is the conditioning factor for argument marking with intransitive verbs. DURBIN \& OJEDA (1978: 70) note that the aspectual opposition in Yucatec Maya has some influence on the focus interpretation of the final $\mathrm{A}$ in VPA clauses.

(d) PRAGMATIC PREFERENCES: This part of the experiment tests if the animacy effects result from genuine constraints determining the role choice in Yucatec Maya, or if they result from a general strategy to assign role pragmatically.

A further parameter which definitively plays a central role in determining argument order is the relative weight of the postverbal arguments, and notably the general preference for extraposing heavy constituents to the right side of the clause. Since our study focuses on the semantic/pragmatic features determining word order, the existing observations on the role of weight have not been included in our experimental targets.

\subsection{Empirical methods and consultants}

Our investigation of Yucatec Mayan argument orders is based on two kinds of empirical evidence. The main evidence comes from a comprehension experiment which was conducted in Yaxley (a village of about 1,000 people located in Quintana Roo, Mexico) during our field period in December 2004. ${ }^{10}$ This experiment will be the main topic of sections $3-4$. The experimental data will be compared to corpus data from spontaneously produced narrative texts in section 5 .

The experiment is designed to investigate the comprehension of Mayan sentences by translation: The consultant hears a recorded sentence uttered by a native speaker, and translates the Mayan utterance into Spanish. Before developing the experiment, a preliminary interrogation took place with 4 consultants, in which we evaluated several elicitation techniques (acceptability judgments, choice of preferred utterance, etc.). On the basis of the preliminary results, we conducted an elaborated version of the experimental setting "meaning elicitation by translation", in which 10 consultants participated. Of these, 4 consultants were young women (age range: 16-25), 3 consultants were young men (age range: $16-28$ ), and 3 consultants were older men (age range: $32-57)$. All our consultants

10 The native speakers are cited with the following abbreviations: AmE= Amedee Colli Colli (f, 34); Dey= Deysy May Pool (f, 25); Ful= Fulgencio Ek Ek (m, 26); Jos= José Luis May Pool (m, 25); Lan= Landy May Pool (f, 21); Ram= Ramón May Cupul (m, 57); Nor= Norma May Pool (f, 31), Ren= Renato May Ek (m, 32); Rig= Rigoberto Tuun Cituk (m, 16); Rob= Roberto Carlos Tamay Requena (m, 17); Suz= Suzana May Cituk (f, 24); Sue= Suemy May Pool (f, 16); Vic= Vicente May PeÑa $(m, 35)$. All consultants were paid for their contribution to the experiments on an honorary basis. 
were residents of Yaxley, they use Yucatec Maya in their everyday communication, and all are bilingual in Spanish to some degree.

\subsection{Experimental design}

In the pilot study, most consultants clearly dispreferred V-initial sentences and corrected them with a topic-comment construction in the AVP order. At the same time, they had a fair amount of difficulty understanding V-initial sentences or disagreed on their interpretation. ${ }^{11}$ In order to eliminate the preference for a topic-comment structure in main clauses, we decided to use subordinate clauses in the final version of the experiment. Our stimuli are illustrated in (6):

\begin{tabular}{|c|c|c|}
\hline Roberto-e' & $t-u$ & $y-a^{\prime} l-a h$ \\
\hline Roberto-TOP & PFV-A. 3 & 0-say-CMPL \\
\hline$t-u$ & $c h i '-a h$ & x-ch'úuppal. \\
\hline 43 & bite-CMPL & F-woman:child \\
\hline
\end{tabular}

'Roberto said that a dog bit a girl/a girl bit a dog.'

The matrix verb in all stimuli is the verb $t-u$ ya'l-ah (PFV-A.3 say-CMPL) 'he said'. This verb was chosen, because it takes the highest position on the binding or deranking hierarchy of complement taking predicates (cf. e.g. Givón 1980, Croft 2001, Cristofaro 2003). In comparison to verbs located lower on this hierarchy, e.g. knowledge verbs or desiderative verbs, verbs of saying show the lowest degree of government of the complement clause, hence they are less likely to impose a control interpretation with respect to the set-A clitic of the subordinate clause. Furthermore, they allow for topicalization in the subordinate clause, and they may be separated from the complement clause by the topic marker - $e$ ' indicating thus, that the subordinated clause is not embedded but juxtaposed to the matrix clause (see Bohnemeyer 1998a, Verhoeven 2005).

For the development of the experimental stimuli, a factorial design was used; 4 conditions with different animacy relations (e.g., human/human, human/non-human, etc.; see section 4.2), and 4 conditions with different definiteness relations (e.g., definite/definite, definite/indefinite, etc.; see section 4.4) were developed. These conditions were combined with 2 aspectual conditions (perfective, imperfective), yielding a total of $(4+4) \times 2=16$ conditions. For each condition there were 4 different lexicalizations resulting in a "basic set" of 64 stimuli (recorded utterances). An "additional set" of 4 conditions was included to check the impact of pragmatic preferences, containing again 4 conditions (e.g., favored agent/favored patient, etc.; see section 4.3) which were implemented in 4 items each, hence adding a further 16 stimuli.

The stimuli were read by two native speakers. The four consultants that participated in the pilot experimental phase had shown a clear divergence in their ordering preferences. In sentences with two animate non-definite postverbal arguments the rates of VPA/VAP interpretations were the following per consultant: $\mathrm{AmE}=3 / 0, \mathrm{RAM}=1 / 2, \mathrm{NoR}=1 / 2, \mathrm{FUL}=0 / 3$. In order that our stimuli represent both types of ordering preferences and their possible prosodic properties, half of the items in each condition were read by the speaker who had shown the clearest VPA preferences in our trial results (АмE), the other half of the items were read by the speaker who had shown most VAP preferences (FUL).

11 A similar result is reported by ENGLAND with respect to Kaqchikel, which is classified as VPA/VAP (ENGLAND 1991: 472). 
In the experimental sessions of the main phase, each of the 10 consultants interpreted a subset of the basic 64 sentences ( 2 items from each condition) in different randomizations. The additional set of 16 sentences that tested the role of pragmatic preferences was performed only by 5 out of 10 consultants. In the experimental sessions, several production tasks were used as fillers, so that the sentences of the "meaning elicitation by translation" experiment were presented in intervals of 3 experimental tasks.

\subsection{Scoring}

Four types of judgments are differentiated in our results (see Fig. 2 below):

(a) an interpretation scored as "VPA" if it contained two postverbal arguments where the final one was the agent;

(b) an interpretation scored as "VAP" if it contained two postverbal arguments where the initial one was the agent;

(c) an interpretation scored as " 1 argument" if both postverbal NPs were interpreted as one argument, namely as a patient, and the person marker (the set-A clitic) of the subordinate verb was controlled by the agent of the matrix verb;

(d) an interpretation scored as "other" in cases where the interpretation of the informant did not correspond to the intended experimental conditions.

The unexpected part of our findings was the high frequency of "1 argument" interpretations (see Fig. 2 below). In these responses, the intended two postverbal arguments are interpreted as one argument: either as a compound $\mathrm{P}$ of the subordinate verb [see example (7a-b)] or as two coordinated Ps [see example (7c)]. In both cases, the subordinate verb is interpreted as controlled by the actor of the matrix verb. Interestingly, a comparable interpretation is reported by ENGLAND (1989) for a Quiché V-initial sentence with two indefinite NPs following the verb. In this construction, Quiché speakers are reported to interpret a third person A which is not coreferential with one of the postverbal lexical arguments. Instead, both postverbal lexical NPs are interpreted as two coordinated Ps (coordination is indicated by means of a pause between the postverbal lexical NPs in Quiché).

(7a) Pedro-e' $t$ - $u \quad y$-a'l-ah $\quad k-u$

Pedro-TOP PFV-A.3 0-say-CMPL PFV-A.3

kìms-ik lòoxnáal chakmol.

kill-INCMPL boxer:AG.NR puma

Intended translation: 'Pedro said that a boxer kills a puma/a puma kills a boxer'.

Elicited translation:'Pedro said that he kills a boxer (named) puma.'

$\begin{array}{lllll}\text { Juan-e' } & t-u \quad y \text {-a'l-ah } & k \text { - } u & \text { kaxant-ik } \\ \text { Juan-TOP } & \text { PFV-A.3 } \quad \text { 0-say-CMPL } & \text { PFV-A.3 } & \text { seek-INCMPL } \\ \text { tsíimin } & \text { tùucháah. } & & \\ \text { horse } & \text { spider.monkey } & & \end{array}$

Intended translation: 'Juan said that a horse seeks a spider monkey/a spider monkey seeks a horse'.

Elicited translation: 'Juan said that he seeks a horse-monkey.' 
(7c) Kristina-e' $\quad t-u \quad y$ - $a^{\prime} l-a h$

Kristina-TOP PFV-A.3 0-say-CMPL

$k$-u $\quad y$-áalkabt-ik xibpal $x$-ch'úuppal.

IPFV-A.3 0-run-INCMPL man:child F-woman:child

Intended translation: 'Kristina said that a girl follows a boy/a boy follows a girl'.

Elicited translation: 'Kristina said that she follows a boy and a girl.'

In the evaluation of our predictions, " 1 argument" interpretations will be generally used as a negative index for the optimality of a transitive clause. The general idea is that the experimental conditions which trigger a high amount of " 1 argument" interpretations contain features that disfavor two postverbal arguments.

\section{Experimental results}

\subsection{General preferences in argument order}

Before we proceed to the analysis of the results on the basis of the conditions tested in the comprehension experiment, we present an outline of the preferred argument orders in the entire data set. Fig. 2 shows the results of 10 consultants, giving an idea of the profile of each one. Fig. 2(a) presents the argument orders gained in the experimental conditions with symmetric transitive clauses, i.e. in the clauses containing two postverbal bare NPs, either both human or both non-human ( 8 sentences per consultant; see conditions 1 and 4 in section 4.2). Fig. 2(b) summarizes the results from the entire basic data set (32 sentences per consultant). (a) symmetric NPs (resp. animacy, definiteness
and weight)

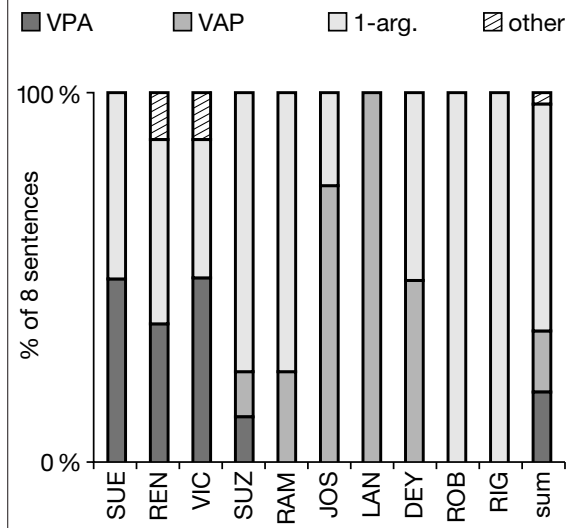

consultants (b) basic set

$\square$ VPA $\square$ VAP $\square$ 1-arg. $\quad$ other

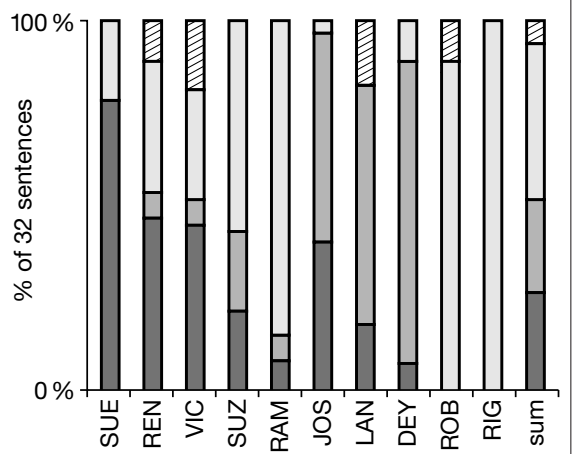

consultants

Fig. 2: Experimental results per speaker 
The outline in Fig. 2 shows that the participants of the experiment display considerable divergence with respect to their argument order preferences. The following four groups are identifiable:

(a) rigid VPA: The first consultant from the left (SUE) is the only speaker with a rigid VPA order;

(b) flexible VPA: The consultants REN, VIC, and Suz show a preference for VPA in symmetric clauses (see Fig. 2a), which is violable in several experimental conditions (see Fig. 2b);

(c) flexible VAP: The consultants RAM, Jos, LAN, and DEY consistently interpreted all symmetric transitive clauses as VAP (see Fig. 2a), but they violated their ordering preferences in other conditions (see Fig. 2b).

(d) 1 argument: The last two consultants on the right side of Fig. 2, namely RoB and RIG, did not interpret two postverbal arguments in any sentence of the data set; instead, they consistently gave " 1 argument" interpretations.

The four groups (a)-(d) do not display any correlation to the social features of our sample as outlined in section 3.2. Thus, members of the group "young women" occur in (a) (SUE), (b) (SUZ) and (c) (LAN, DEY), members of the group "young men" occur in (c) (Jos) and (d) (RoB, RIG), and members of the group "elder men" occur in (b) (REN, VIC) and (c) (RAM). As mentioned in 3.2, all consultants live in the same speech community, they use Yucatec Maya in their everyday communication, and all are bilingual in Spanish. Since the social characteristics of the sample are quite homogeneous, we do not assume any internal sociolectal variation, but rather instability of the constraints under investigation.

In the discussion of the conditions in sections 4.2-4.5, we will inspect the judgments of the speakers who have been sensible to the experimental conditions violating their ordering preferences under certain circumstances, i.e. the groups (b) and (c).

\subsection{Animacy}

One of the factors reported to determine postverbal order in Mayan languages is animacy (cf. AISSEN 1992: 44; 1997). In order to inspect the effects of animacy, we have developed a number of stimuli reflecting the four possible constellations of human/nonhuman postverbal arguments (see Table 1). The experimental conditions do not include the whole spectrum of animacy asymmetries, but only one minimal opposition at the highest animacy level: "human" vs. "non-human". The lexicalization of the resulting conditions is illustrated in examples $(8 \mathrm{a}-\mathrm{d})$.

\begin{tabular}{|l|ll|}
\hline & $\mathrm{NP}_{1}$ & $\mathrm{NP}_{2}$ \\
\hline $\mathrm{C} 1$ & human & human \\
$\mathrm{C} 2$ & human & non-human \\
$\mathrm{C} 3$ & non-human & human \\
$\mathrm{C} 4$ & non-human & non-human \\
\hline
\end{tabular}

Table 1: Animacy effects: conditions 
(8)

\begin{tabular}{|c|c|c|}
\hline Maria-e' & $t-u$ & $y-a^{\prime} l-a h \ldots$ \\
\hline Maria-тоP & PFV-A.3 & 0 -say-CMPL \\
\hline
\end{tabular}

...k-u y-áalkabt-ik xibpal x-ch'úuppal.

IPFV-A.3 0-run-INCMPL man:child F-woman:child

'... a boy drives away a girl/a girl drives away a boy.'

...k-u y-áalkabt-ik xibpal k'éek'en.

IPFV-A.3 0-run-INCMPL man:child pig

'... a boy drives away a pig/a pig drives away a boy.'

...k-u y-áalkabt-ik úulum $x$-ch'úuppal.

IPFV-A.3 0-run-INCMPL turkey F-woman:child

'... a turkey drives away a girl/a girl drives away a turkey.'

...k-u $\quad y$-áalkabt-ik úulum k'éek'en.
IPFV-A.3 $\quad$ 0-run-INCMPL turkey pig
'... a turkey drives away a pig/a pig drives away a turkey.'

The four conditions in Table 1 have been lexicalized in 4 items which are presented in Table 2. For the symmetric conditions both humans or both non-humans of the respective item have been used. In the asymmetric conditions, the stimulus contained the elements "human 1" and "non-human 1". The entire set has been implemented in two aspects, i.e. completive and incompletive. This design yielded a total of $4 \times 4 \times 2=32$ experimental sentences. 10 consultants have interpreted two sentences in each condition in different randomizations.

\begin{tabular}{|c|c|c|c|c|c|}
\hline & verb & non-human 1 & non-human 2 & human 1 & human 2 \\
\hline item 1 & $\begin{array}{l}\text { áalkabt } \\
\text { 'follow' }\end{array}$ & $\begin{array}{l}\text { k'éek'en } \\
\text { 'pig' }\end{array}$ & $\begin{array}{l}\text { úulum } \\
\text { 'turkey' }\end{array}$ & $\begin{array}{l}\text { xibpal } \\
\text { 'boy' }\end{array}$ & $\begin{array}{l}\text { xch'úuppal } \\
\text { 'girl' }\end{array}$ \\
\hline item 2 & $\begin{array}{l}\text { kìms } \\
\text { 'kill' }\end{array}$ & $\begin{array}{l}\text { báalam } \\
\text { 'jaguar' }\end{array}$ & $\begin{array}{l}\text { chakmol } \\
\text { 'puma' }\end{array}$ & $\begin{array}{l}\text { lòoxnáal } \\
\text { 'boxer' }\end{array}$ & $\begin{array}{l}\text { ts'onnáal } \\
\text { 'hunter' }\end{array}$ \\
\hline item 3 & $\begin{array}{l}\text { pakt } \\
\text { 'look at' }\end{array}$ & $\begin{array}{l}\text { pèek' } \\
\text { 'dog' }\end{array}$ & $\begin{array}{l}\text { mìis } \\
\text { 'cat' }\end{array}$ & $\begin{array}{l}\text { yùum } \\
\text { 'senor' }\end{array}$ & $\begin{array}{l}\text { kolnáal } \\
\text { 'farmer' }\end{array}$ \\
\hline item 4 & $\begin{array}{l}\text { kaxant } \\
\text { 'seek' }\end{array}$ & $\begin{array}{l}\text { tsíimin } \\
\text { 'horse' }\end{array}$ & $\begin{array}{l}\text { tùucháah } \\
\text { 'monkey' }\end{array}$ & $\begin{array}{l}\text { wàach } \\
\text { 'soldier' }\end{array}$ & $\begin{array}{l}\text { (h)ts'àak } \\
\text { 'physician' }\end{array}$ \\
\hline
\end{tabular}

Table 2: Animacy effects: experimental items

The interpretations given for these sentences are summarized in Fig. 3 (this figure only contains the data of the 7 consultants who were sensible to the experimental conditions, see section 4.1).

There are different kinds of animacy effects, which are reported for several languages of the Mayan language family. First, there are effects which relate to the cross-linguistic preference for direct alignment, i.e. that lower arguments in the hierarchy of thematic roles 


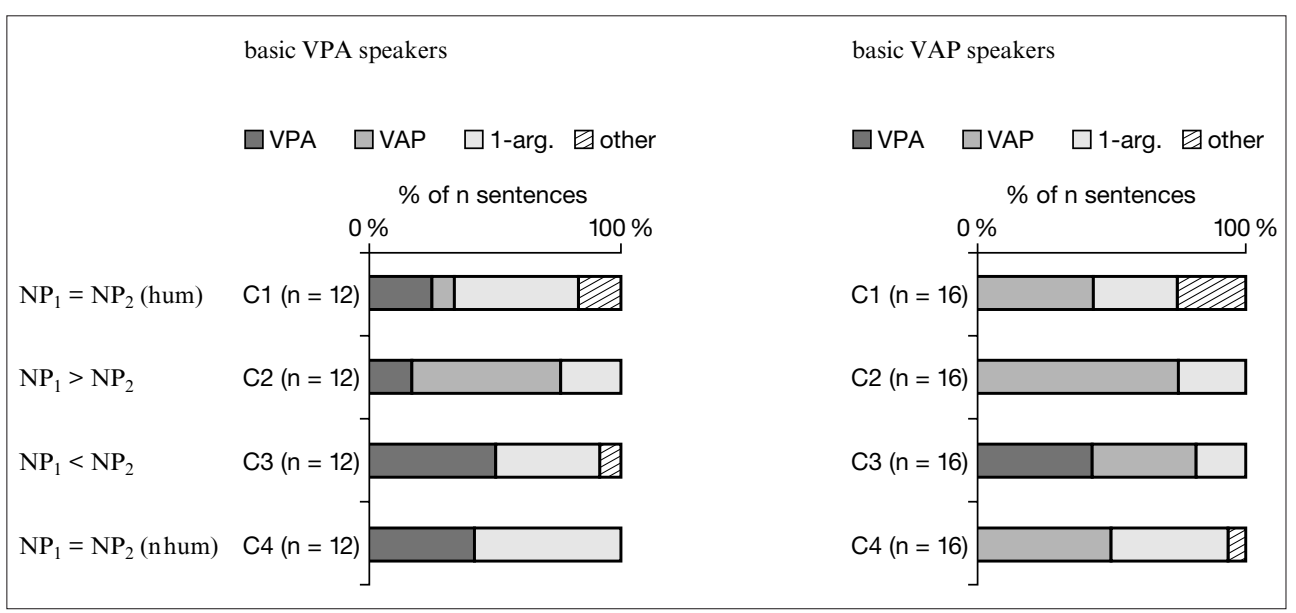

Fig. 3: Animacy effects: results

(i.e. agent $>$ patient), do not outrank higher arguments in terms of the animacy hierarchy (i.e. animate > inanimate) (see AIssen 1997: 711; 1999: 695). In general, it is assumed for head-marking languages that they have a greater ordering flexibility which is often determined by inherent properties of the NPs like animacy (see vaN VALIN 1987: 393, Nichols 1986: 104). vaN VALIN (1987: 376) illustrates this tendency with the example of Lakhota, in which ordering preferences are ignored and arguments may occur in either order if argument choice is disambiguated by animacy or number.

It is indeed reported for different Mayan languages with flexible word orders that if the transitive clause arguments do not have equal status in animacy, the ordering preferences are more flexible (see ENGLAND 1991: 482). A tendency for animacy to outrank ordering preferences in the role choice for postverbal lexical NPs has been observed for Yucatec Maya (see BoHNEMEYer 1998a: 163; DuRbin \& OJEDA 1978). In our comprehension experiment, a preference for harmonic alignment of animacy and thematic role is expected to have the following effect on the data in cases where canonical ordering preferences and animacy features are in conflict:

Harmonic alignment hypothesis: If animacy outranks argument order in the agent choice in Yucatec Maya, then we expect that:

Given a $\mathrm{V} \prec \mathrm{NP}_{1} \prec \mathrm{NP}_{2}$ stimulus:

- speakers that favor VAP when $\mathrm{NP}_{1}=\mathrm{NP}_{2}$ in animacy will tend to interpret VPA when $\mathrm{NP}_{1}<\mathrm{NP}_{2}$ in animacy.

- speakers that favor VPA when $\mathrm{NP}_{1}=\mathrm{NP}_{2}$ in animacy will tend to interpret VAP when $\mathrm{NP}_{1}>\mathrm{NP}_{2}$ in animacy.

The harmonic alignment hypothesis is broadly confirmed by the results in Fig. 3. The speakers favoring VPA in the symmetric conditions $\mathrm{C} 1$ and $\mathrm{C} 4$, turn to VAP when a higher animate occurs immediately after the verb and a lower animate clause finally (see C2). On the other hand, the speakers favoring VAP in symmetric transitive clauses, give more VPA judgments when the human participant is clause final (see C3). Fig. 3 shows that animacy generally outranks ordering preferences, but it does not totally eliminate them (1 VPA speaker and 3 VAP speakers insisted on their preferred order at half their judgments on 
asymmetric transitive clauses). Recall that Fig. 3 contains the speakers with flexible word orders. Another speaker in our sample did not violate her ordering preferences in any experimental condition (see SuE in Fig. 2b).

Animacy is a fundamental means for the resolution of ambiguities in role choice. Clauses with two lexical NPs which are equal in animacy may be penalized by a general constraint on avoiding ambiguity. This constraint is expected to be particularly important in a headmarking language with flexible word order, where animacy has a crucial contribution to the choice of thematic role. The effects of this constraint, namely that potentially ambiguous transitive clauses with two postverbal lexical NPs are avoided, have already been mentioned for Yucatec Maya (see Bohnemeyer 1998a: 163). Instead of transitive clauses, Yucatec Maya speakers are reported to prefer alternative constructions, e.g., passivization, topicalization, clefting, etc. In terms of our experiment, if potentially ambiguous sentences are disfavored, then we expect more " 1 argument" interpretations in the corresponding conditions.

Avoid ambiguity hypothesis: If potentially ambiguous transitive clauses with two postverbal lexical NPs are generally avoided in Yucatec Maya, then:

Given a $\mathrm{V} \prec \mathrm{NP}_{1} \prec \mathrm{NP}_{2}$ stimulus, speakers of either VXY group will tend to interpret " 1 argument" when $\mathrm{NP}_{1}=\mathrm{NP}_{2}$ in animacy.

If a general constraint that penalizes ambiguous utterances holds in Yucatec Maya, this is expected to disfavor the sentences in which both arguments are equal in terms of animacy. Fig. 3 confirms this expectation: in the symmetrical conditions 1 "human-human" and 4 "non human-non human", the index of "1 argument" interpretations is higher.

A further group of animacy effects reported for Mayan languages concerns the case that word order is directly determined by certain animacy features. NORMAN \& CAMPBELL (1978: 146) claim on the basis of Huastec and Tzeltal data that Proto-Maya had canonical VAP order when $\mathrm{A}=\mathrm{P}$ in the animacy hierarchy, but VPA, when $\mathrm{A}>\mathrm{P}^{12}$ The clause final position for higher animates is in line with the assumption of given status for clause final subjects (see discussion in section 4.4).

Clause final animate hypothesis: If the clause final argument is preferred for higher animates in Yucatec Maya, then:

Given a $\mathrm{V} \prec \mathrm{NP}_{1} \prec \mathrm{NP}_{2}$ stimulus, speakers that favor VAP when $\mathrm{NP}_{1}=\mathrm{NP}_{2}$ in animacy will better accept VPA interpretations when $\mathrm{NP}_{1}<\mathrm{NP}_{2}$ in animacy, than VPA speakers will accept VAP when $\mathrm{NP}_{1}>\mathrm{NP}_{2}$ in animacy.

In contrast to this prediction, Fig. 3 (C2 and C3) shows that higher animates at the first postverbal position triggered VAP more successfully than higher animates at the clause final position triggered VPA (note also that VPA speakers gave more " 1 argument" interpretations when $\mathrm{NP}_{1}<\mathrm{NP}_{2}$ than VAP speakers when $\mathrm{NP}_{1}>\mathrm{NP}_{2}$ ).

Several studies in language production and comprehension have shown the tendency for animates to occur early in the utterance (see Bock et al.1992). The general argument is that animate referents are easily retrievable for memory and hence inherently more accessible in discourse than inanimate ones. Of particular interest is how this cross-linguistic preference interacts with a canonical patient-agent order.

12 This claim has not been confirmed for Tenejapan Tzeltal in a more recent corpus study (see RoBinson 2002: 54-55, 76; see also section 2.1 above). 
Animate first hypothesis: If animate first constructions are preferred in Yucatec Maya, then:

Given a $\mathrm{V} \prec \mathrm{NP}_{1} \prec \mathrm{NP}_{2}$ stimulus, speakers that favor VPA when $\mathrm{NP}_{1}=\mathrm{NP}_{2}$ in animacy will better accept VAP interpretations when $\mathrm{NP}_{1}>\mathrm{NP}_{2}$ in animacy, than VAP speakers will accept VPA when $\mathrm{NP}_{1}<\mathrm{NP}_{2}$ in animacy.

Our data shows a slight preference for animate first constructions. Speakers with basic VPA order gave $58 \%$ VAP interpretations in $\mathrm{C} 2$, in which $\mathrm{NP}_{1}>\mathrm{NP}_{2}$ in animacy, whereas speakers with basic VAP order gave $43 \%$ VPA interpretations in $\mathrm{C} 3$, in which $\mathrm{NP}_{1}<\mathrm{NP}_{2}$ in animacy (see Fig. 3).

In sum, the results of this part of our experiment show that Yucatec Mayan speakers violate their ordering preferences in order to satisfy the universal preference for harmonic alignment, i.e. in order to assign the agent role to the higher animate. Additionally, our speakers disfavor transitive clauses with two postverbal lexical NPs, which are equal in animacy, and show a slight preference for animate first constructions.

\subsection{Pragmatic preferences}

So far we have considered ambiguous sentences, where both available choices of agent and patient role are equally probable on pragmatic grounds, e.g. there is no pragmatic preference for a man to run after a pig or vice versa. In this section, we will consider the case in which a strong inference based on verb semantics favors one interpretation over the other. This data set is intended to supplement the animacy effects observed in section 4.2. The question is, if the preference for harmonic alignment of animacy and thematic role hierarchies is a genuine rule in this language or if it results from a general tendency to assign thematic role pragmatically and not structurally. I.e., are the results in section 4.2 licensed by a rule favoring higher animates for agents, or by a general tendency to choose agents on the basis of pragmatic assumptions?

In order to inspect the relation between harmonic alignment and pragmatic preferences, we have developed a set of sentences of the general type "lower animate acts upon a higher animate", in which the pragmatic preference conflicts the preference for higher animate agents. The four conditions are presented in Table 3. The first two conditions contain two bare NPs, the two later conditions contain two indefinite NPs. In conditions 1 and 3 the pragmatically favorite agent is the clause final NP, while in conditions 2 and 4 the pragmatically favorite agent is the first postverbal NP. The 4 conditions are exemplified in (9a-d).

\begin{tabular}{|l|ll|}
\hline & $\mathrm{NP}_{1}$ & $\mathrm{NP}_{2}$ \\
\hline $\mathrm{C} 1$ & bare NP, favorite patient & bare NP, favorite agent \\
$\mathrm{C} 2$ & bare NP, favorite agent & bare NP, favorite patient \\
$\mathrm{C} 3$ & indefinite NP, favorite patient & indefinite NP, favorite agent \\
$\mathrm{C} 4$ & indefinite NP, favorite agent & indefinite NP, favorite patient \\
\hline
\end{tabular}

Table 3: Pragmatic preferences: conditions 
(9) Roberto-e' $t$ - $u \quad y$-a'l-ah...

Roberto-TOP PFV-A.3 0-say-CMPL

'Roberto said that...'

(9a) ...t-u chi'-ah x-ch'úuppal pèek'.

PFV-A.3 bite-CMPL F-woman:child dog

'... a dog bit a girl/a girl bit a dog.'

(9b) c..t-u chi'-ah pèek' x-ch'úuppal.

PFV-A.3 bite-CMPL dog F-woman:child

'... a dog bit a girl/a girl bit a dog.'

(9c) ...t-u chi'-ah hun-túul x-ch'úuppal hun-túul pèek'.

PFV-A.3 bite-CMPL one-CL.AN F-woman:child one-CL.AN dog '... a dog bit a girl/a girl bit a dog.'

...t-u chi'-ah hun-túul pèek' hun-túul x-ch'úuppal.

PFV-A.3 bite-CMPL one-CL.AN dog one-CL.AN F-woman:child

'... a dog bit a girl/a girl bit a dog.'

The lexicalizations for these conditions are presented in Table 4: 'a dog bites a girl', 'a mosquito bites a seller', 'a snake strangles a farmer', and a 'dog barks at a thief'.

\begin{tabular}{|l|lll|}
\hline & verb & favorite agent & favorite patient \\
\hline item 1 & chi' 'bite' & pèek' 'dog' & xch'úuppal 'girl' \\
item 2 & chi' 'bite' & $k$ 'oxol 'mosquito' & $k$ konol 'seller' \\
item 3 & yets'kàalt 'strangle' & $k$ àan 'snake' & kolnáal 'farmer' \\
item 4 & tòoholt 'bark at' & pèek' 'dog' & òokol 'thief' \\
\hline
\end{tabular}

Table 4: Pragmatic preferences: experimental items

These sentences have been interpreted by only 5 consultants (due to limitations in our field plan) in different randomizations. In the data, we recognized some misunderstandings in item 3 from several speakers induced by a second verb meaning. In the summary of the data in Fig. 4 this item is excluded across conditions.

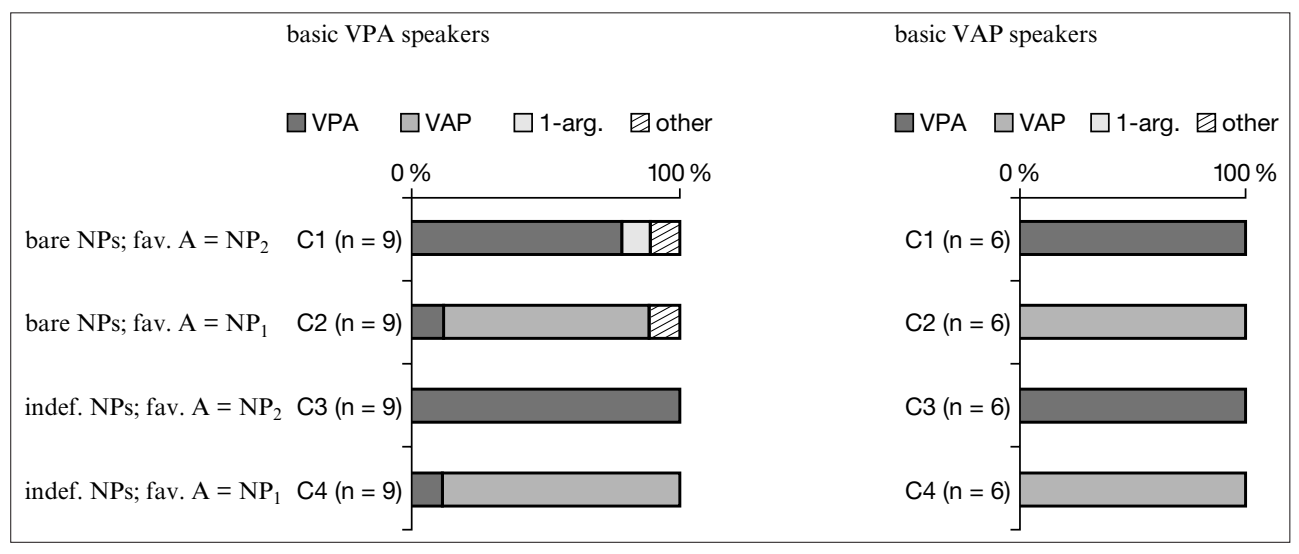

Fig. 4: Pragmatic preferences: results 
In all sentences of this data set, a strong (but still cancelable) inference that the lower animate is the only possible agent is provided by the verb semantics, as for instance in an event of biting in which a dog and a girl are involved. Given that in the absence of such inference, the higher animate is the preferred agent (harmonic alignment, see section 4.2), this set of conditions will show if this preference for higher animate agents is outranked by a constraint avoiding pragmatically non-well-formed sentential meanings.

Pragmatic prominence hypothesis: If pragmatic preferences outrank harmonic alignment in Yucatec Maya, then:

Given a $\mathrm{V} \prec \mathrm{NP}_{1} \prec \mathrm{NP}_{2}$ stimulus:

- speakers that favor VAP when $\mathrm{NP}_{1}>\mathrm{NP}_{2}$ in animacy will tend to interpret VPA when $\mathrm{NP}_{2}=$ favored $\mathrm{A}$;

- speakers that favor VPA when $\mathrm{NP}_{2}>\mathrm{NP}_{1}$ in animacy will tend to interpret VAP when $\mathrm{NP}_{1}=$ favored $\mathrm{A}$.

The data in Fig. 4 confirms this hypothesis. Though the stimuli do not satisfy the harmonic alignment constraint, the consultants processed all of them without problem and interpreted all sentences in inverse alignment. Their ordering preferences are almost completely eliminated through the pragmatic preference, and this holds uniformly for both groups of VPA and VAP speakers. Thus, it is clear that the satisfaction of pragmatic preferences is the prominent factor in their interpretations and that the role choice is determined by pragmatics.

Furthermore, and building upon the corresponding hypothesis in 4.2, we expect that the constraint of avoiding ambiguity will be even better satisfied if the verb provides a strong inference for the choice of its arguments.

Avoid ambiguity hypothesis: If ambiguous transitive clauses with two postverbal lexical NPs are generally avoided in Yucatec Maya, then:

Given a $\mathrm{V} \prec \mathrm{NP}_{1} \prec \mathrm{NP}_{2}$ stimulus, speakers of either VXY group will give fewer "1 argument" interpretations when the verb semantics provide a strong inference for the argument choice than in conditions where simply $\mathrm{NP}_{1} \neq \mathrm{NP}_{2}$ in animacy.

The results in Fig. 4 clearly confirm this hypothesis. The consultants interpreted the sentences of this set with the highest consistency and gave the fewest " 1 argument" interpretations. This result shows that the structure with two postverbal arguments is comprehensible if pragmatics provide a hint for the role assignment.

It should be noticed that if Yucatec Maya had obviation traits with respect to the distinction human/non-human, as it has been observed for other Meso-American languages, the results would be different. Since the inference based on the verb semantics leads to an inverse alignment where the lower animate acts upon the higher one, then all the stimuli of this part of the experiment would present strong suboptimality: the speakers should choose among a clause with bad alignment (lower animate acts upon the higher) and a clause with bad pragmatics (e.g., a girl biting a dog).

Obviation hypothesis: If there are obviative traits with respect to the human/non-human distinction in Yucatec Maya, then:

Given a $\mathrm{V} \prec \mathrm{NP}_{1} \prec \mathrm{NP}_{2}$ stimulus, speakers of either VXY group will tend to interpret "1 argument" when $\mathrm{NP}_{\mathrm{i}}=$ favorite $\mathrm{A}$ and $\mathrm{NP}_{\mathrm{i}}<\mathrm{NP}_{\mathrm{j}}$ in animacy. 
The favorite agent is lower in animacy than the favorite patient in all conditions of this part of the experiment. The results in Fig. 4 do not confirm the obviation hypothesis with respect to the human/non-human distinction.

In sum, pragmatically clear clauses have been interpreted with considerable stability across speakers and across items. Pragmatics outrank the ordering preferences of all speakers as well as the preference for harmonic alignment. Moreover, pragmatically clear sentences have been interpreted with greater consensus by all informants: the index of "1 argument" interpretations is lower than in any other sentence set in our experiment.

\subsection{Definiteness}

Definiteness has often been cited among the factors that influence postverbal argument orders in Mayan languages (cf. Aissen 1992: 44; Duncan 2003; Durbin \& OJeda 1978: 71; ENGLAND 1991). Our experimental design contains three conditions on definiteness which are presented in Table 5 and exemplified in (10). The conditions contain the following combinations of definiteness in the postverbal NPs: "definite-definite" [see condition 1 and example (10a)], "definite-indefinite" [see condition 2 and example (10b)], "indefinitedefinite" [see condition 3 and example (10c)]. A fourth condition in the experimental design was planned to account for the role of deictic clitics in combination with the definite markers (cf. e.g. LeHMANN 1998). Since the results of these elements have not been consistent enough to allow for any generalizations, they are excluded from our report.

\begin{tabular}{|l|ll|}
\hline & $\mathrm{NP}_{1}$ & $\mathrm{NP}_{2}$ \\
\hline $\mathrm{C} 1$ & definite & definite \\
$\mathrm{C} 2$ & definite & indefinite \\
$\mathrm{C} 3$ & indefinite & definite \\
\hline
\end{tabular}

Table 5: Definiteness effects: conditions

$$
\begin{array}{lll}
\text { Jorge-e } & t-u & y \text { - } a^{\prime} l-a h . . \\
\text { Jorge-TOP } & \text { PFV-A.3 } & 0 \text {-say-CMPL } \\
\text { 'Jorge said (that)...' } &
\end{array}
$$

(10a) ...k-u hats'-ik le chukkay-o' le tóokchúuk-o'. IPFV-A.3 beat-INCMPL DEF catch:fish-D2 DEF burn:charcoal-D2 '...the fisherman beats the charcoal maker/the charcoal maker beats the fisherman.'

(10b) ...k-u hats'-ik le chukkay hun-túul tóokchúuk-o'. IPFV-A.3 beat-INCMPL DEF catch:fish one-CL.AN burn:charcoal-D2 ...the fisherman beats a charcoal maker/a charcoal maker beats the fisherman.'

(10c) ...k-u hats'-ik hun-túul chukkay le tóokchúuk-o'. PFV-A.3 beat-INCMPL one-CL.AN catch:fish DEF burn:charcoal-D2 .... fisherman beats the charcoal maker/the charcoal maker beats a fisherman.'

Four items were developed for each condition from the lexical elements in Table 6, once in the completive and once in the incompletive aspect, resulting in a total of $3 \times 4 \times 2=24$ 
experimental sentences. Exactly as in the animacy set, 10 consultants judged half of these sentences in different randomizations.

\begin{tabular}{|l|lll|}
\hline & verb & $\mathrm{NP}_{1}$ & $\mathrm{NP}_{2}$ \\
\hline item 1 & hats' & chukkay & tóokchúuk \\
& 'beat' & 'fisherman' & 'charcoal maker' \\
item 2 & cha'nt & konnòok' & kolnáal \\
& 'contemplate' & 'dress seller' & 'farmer' \\
item 3 & t'àan(t) & (h)mèencha'n & lòoxnáal \\
& 'call' & 'fiesta organizer' & 'boxer' \\
item 4 & xíimbat & (h)mèen & (h)k'ìin \\
& 'visit' & 'shaman' & 'sacerdote' \\
\hline
\end{tabular}

Table 6: Definiteness effects: experimental items

The interpretations of 7 consultants are presented in Fig. 5 (the results of the remaining 3 consultants are discussed in section 4.1).

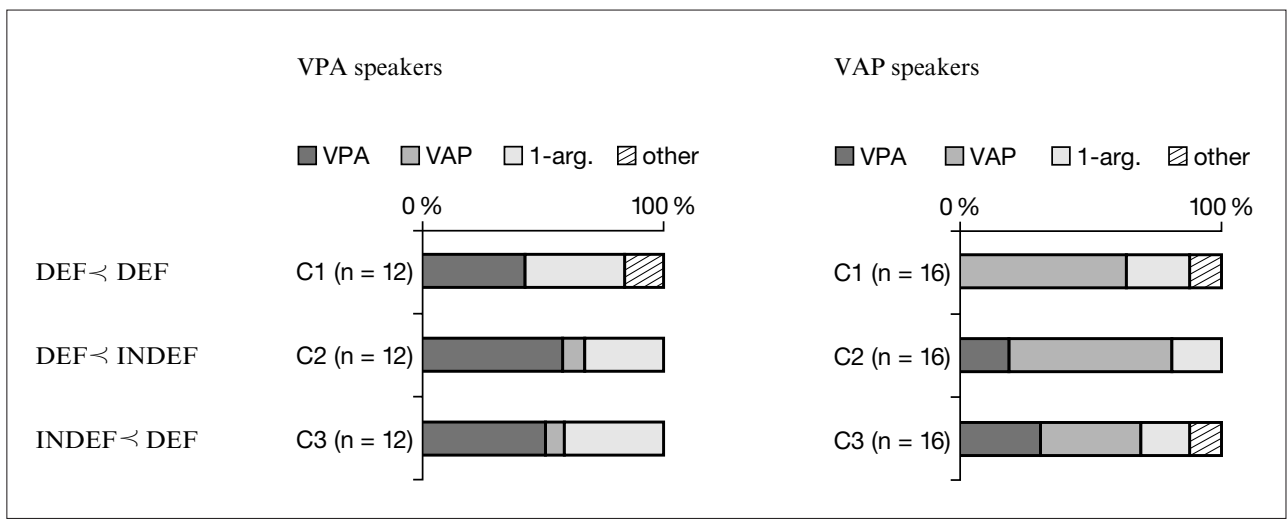

Fig. 5: Definiteness effects: results

Definiteness, like animacy, is associated with the thematic role hierarchy in a binary dimension, involving the two scales [Def > Indef] and [Ag > Pat] (see BroAdwell 2000: 8): the harmonic alignment of both scales results in the preference for definite agents and indefinite patients. Duncan (2003: 167) claims that in Tzutujil an indefinite patient and a definite (clause-final) agent form a well-formed (though ambiguous) transitive clause. In contrast, the non-favored combination of an indefinite patient and an agent which is unmarked for definiteness results in a non-grammatical sentence. In terms of our comprehension experiment, definiteness is expected to influence the interpretation in the same way as animacy:

Harmonic alignment hypothesis: If definiteness outranks argument order in the agent choice in Yucatec Maya, then:

Given a $\mathrm{V} \prec \mathrm{NP}_{1} \prec \mathrm{NP}_{2}$ stimulus: 
- speakers that favor VAP when $\mathrm{NP}_{1}=\mathrm{NP}_{2}$ in definiteness will tend to interpret VPA when $\mathrm{NP}_{1}<\mathrm{NP}_{2}$ in definiteness;

- speakers that favor VPA when $\mathrm{NP}_{1}=\mathrm{NP}_{2}$ in definiteness will tend to interpret VAP when $\mathrm{NP}_{1}>\mathrm{NP}_{2}$ in definiteness.

The harmonic alignment hypothesis predicts that speakers will deviate from their default judgments in sentences with a definite and an indefinite NP, when the latter occurs in their favorite A position. Thus, VPA speakers are expected to output VAP in C2 and VAP speakers are expected to output VPA in C3. These predictions have been proven to be true in the results, but surprisingly both groups of speakers have also partly produced the non-favorite interpretations in the conditions that were expected to reinforce their ordering properties. There is no explanation for this part of the collected data according to our experimental hypotheses. However, the overall impression is that definiteness has less influence on the speakers' interpretation of postverbal argument order than animacy (compare Fig. 5 with Fig. 3).

Another point is the interaction between definiteness and the avoid ambiguity constraint, which has been shown to have a crucial impact in the interpretations presented in sections 4.2-4.3. Clauses with two NPs that are equal in definiteness are likely to be ambiguous and may be penalized by the avoid ambiguity constraint. This is reported for Tzutujil by DAYLEY (1985: 305), who claims that two definite or two indefinite postverbal NPs are ungrammatical in this language (DuncAN 2003: 168 refutes this judgment). Furthermore, if the two arguments have a clear difference in definiteness (agent is definite and patient either indefinite or unmarked for definiteness), then either order is possible (DUNCAN 2003: 170). The corresponding prediction in our comprehension experiment is formulated as follows:

Avoid ambiguity hypothesis: If potentially ambiguous transitive clauses with two postverbal lexical NPs are generally avoided in Yucatec Maya, then:

Given a $\mathrm{V} \prec \mathrm{NP}_{1} \prec \mathrm{NP}_{2}$ stimulus, speakers of either VXY group will tend to interpret " 1 argument" when $\mathrm{NP}_{1}=\mathrm{NP}_{2}$ in definiteness.

The hypothesis concerning ambiguity is parallel to the corresponding hypothesis in the animacy conditions (cf. section 4.2): when the two lexical NPs are equal in terms of the definiteness hierarchy (see first condition in Fig. 5), then the index of "1 argument" interpretations increases. This prediction has also been confirmed in our results. The frequency of "1 argument" interpretations within the interpretations in our experiment was: VPA speakers, 0,5 for C1, 0,3 for C2, 0,4 for C3; VAP speakers, 0,28 for $\mathrm{C} 1,0,2$ for $\mathrm{C} 2$, and 0,21 for C3. So, the speakers disfavored sentences with two definite arguments, which is in line with observations made for other Mayan languages, e.g., Tzutujil in DAYLEY (1985: 305).

Another two hypotheses aim to inspect special ordering preferences for definite NPs. A special problem is the discourse status of a final agent in "subject-final" languages. Clause-final subjects entail a conflict to the preference for discourse topics to be posited at the beginning of the clause (KEENAN 1978: 304). It has been assumed for clause final "subjects" in Malagasy that these arguments bear given information, hence clause-final subjects in this language are obligatorily definite (see Keenan 1976: 253; Pearson 2001). As concerns Mayan languages, it has been argued for Kaqchikel that only definite agents are allowed in the clause final position; if the agent is indefinite, then it must appear in the preverbal position triggering actor focus morphology on the verb (BROADWELL 2000: 7). An 
implicational observation for Yucatec Maya is made by Durbin \& OJeDA: if the second postverbal argument is not marked as definite, then it is not possible for the first one to be marked as definite (Durbin \& OJEDA 1978: 73). Thus, the following hypothesis should be tested in our experiment:

Clause final background hypothesis: If the agent-final position is reserved for given information in Yucatec Maya, then:

Given a $\mathrm{V} \prec \mathrm{NP}_{1} \prec \mathrm{NP}_{2}$ stimulus, speakers of either VXY group will refuse to interpret VPA when $\mathrm{NP}_{2}=$ indefinite.

The next question to be inspected through the results is the role of given-before-new preferences in a language with canonical patient-before-agent order. The order givenbefore-new is assumed as cross-linguistically preferred, since it helps the listener to link the sentence to the common ground before the new information is introduced (CLARK \& Clark 1977; Clark \& Haviland 1977). Following this cross-linguistic tendency, definite NPs should have an advantage to occur early in the clause.

Given-before-new hypothesis: If the given information precedes new information in Yucatec Maya, then:

Given a $\mathrm{V} \prec \mathrm{NP}_{1} \prec \mathrm{NP}_{2}$ stimulus, speakers that favor VPA when $\mathrm{NP}_{1}=\mathrm{NP}_{2}$ in definiteness, will better accept VAP interpretations when $\mathrm{NP}_{1}>\mathrm{NP}_{2}$ in definiteness, than VAP speakers will accept VPA when $\mathrm{NP}_{1}<\mathrm{NP}_{2}$ in definiteness.

The data obtained do not support any of the last two hypotheses. According to the clause final background hypothesis, there should be an advantage for definite NPs at the end of the clause; the given-before-new preference on the other hand, is expected to favor definite NPs first. As it may be seen in Fig. 5, there is no consistent preference for either order in our data. The speakers deviated from their ordering preferences in both non-symmetrical conditions, without showing any preference for one or the other order.

\subsection{Aspect}

Verbal aspect has a crucial impact on argument coding in Yucatec Maya, since it is the conditioning factor for split intransitivity in this language (section 2.2): the $\mathrm{S}$ of intransitive verbs is encoded like the $\mathrm{A}$ of transitive verbs in incompletive aspect, and like the $\mathrm{P}$ of transitive verbs in the completive aspect.

In order to investigate possible effects of verbal aspect on word order, the sets of sentences presented in sections 4.2 (animacy conditions) and 4.4 (definiteness conditions) have been tested in two aspects, completive and incompletive: it is exactly these aspects which trigger different S-coreference markers of intransitive verbs (see section 2.2). The 8 conditions presented in sections 4.2 and 4.4 were implemented in 4 items, once in each aspect (total $8 \times 4=32$ experimental sentences). Each informant was given half of the stimuli ( 2 per condition), hence he interpreted 16 recorded sentences. The results obtained show that there is no substantial change of the ordering preferences conditioned by the verbal aspect. The "transitive" interpretations of VPA speakers were: $70 \%$ "VPA" vs. $29 \%$ "VAP" in incompletive aspect, and $82 \%$ "VPA" vs. $17 \%$ "VAP" in completive aspect. The "transitive" interpretations of VAP speakers were $25 \%$ "VPA" vs. $75 \%$ "VAP" in incompletive aspect, and $24 \%$ "VPA" vs. $75 \%$ "VAP" in completive aspect. 


\subsection{Sentential prosody}

One further possible factor is the role of intonation in the interpretation of our stimuli, since the consultants have heard (rather than read) the experimental material. Though there is not yet a thorough analysis of Yucatec Mayan sentential prosody, intonation has been hypothesized as a triggering factor for VAP and VPA interpretations in DURBIN \& OJEDA $(1978: 70,73)$.

As noted in section 3.3, the sentences were read by two native speakers who had shown respectively the maximal preference for the VPA and VAP orderings in the preliminary version of the experiment (FUL gave only VAP interpretations, AME only VPA interpretations). Each speaker read two sentences per condition in order to exclude the judgments in a certain condition depending on the prosody of a particular speaker. Two weeks after the recording, these two speakers were invited to interpret the entire data set. In accordance with their initial judgments, FuL translated all sentences exclusively with VAP and AME translated all sentences with VPA. Under these considerations an impact of the intonation on the elicited judgments should be ruled out.

\section{Mapping experimental data onto naturalistic data}

The data of the comprehension experiment presented in section 4 showed that the divergence of interpretation across speakers is considerably high; in a small sample of speakers we have identified four subgroups with diametrically divergent judgments: a subgroup of rigid VPA, two subgroups of flexible VPA and flexible VAP respectively and a subgroup which only produced "1 argument" interpretations (see section 4.1). The question is how such conflicting grammars co-exist in natural language communication.

In section 4.1 we argued that the variation in the judgments does not reflect a sociolectal variation of the speakers in question, but rather that it results from the instability of the constraints in question. This view is supported by the results of our experimental conditions. The role choice for postverbal arguments is mostly determined by pragmatic preferences as shown in 4.3. In the current section, we will show on the basis of naturalistic data that the instability in the role choice for postverbal arguments as well as the high index of " 1 argument" interpretations in our data are related to the seldom occurrence of transitive clauses with two postverbal lexical NPs in spontaneous language production.

Recent corpus studies in Mayan languages within the framework of Preferred Argument Structure show that transitive sentences with two lexical NPs are very rare in corpora. It has been shown that in Itzaj, Mam, Mocho, Kanjobal, Sacapulteco, Tectiteco, and Tzeltal the occurrence of transitive clauses with two lexical NPs falls within the domain 0,002<p<0,1 (see Hofling 2003: 387; England \& Martin 2003: 149; Keenan 1978: 280; RoBinson 2002: 60). Yucatec Maya shows similar properties in our corpus: the frequency of transitive clauses with two lexical NPs in Table 7 is 0,05 in the text based measurement and 0,12 in the verb based measurement.

The low occurrence of transitive clauses in Maya is not a peculiarity of this language family. Within the framework of Preferred Argument Structure (see Du BoIs et al. 2003), it is argued that similar results hold cross-linguistically. The point at issue is the possible impact of this cross-linguistic generalization on a head-marking verb initial language. Yucatec Maya shares with many other verb-initial languages the property of having 
different orders for the "all-new" and "topic-comment" discourse conditions. The preferred information structure for transitive clauses in language production is the "topic-comment" one. Even if contextual factors are absent, speakers tend to create some information structural relief for clauses with more than one argument. This means that in languages which display different orders for topic-comment and pragmatically neutral conditions, the latter orders are expected to be rare in spontaneously produced texts. These expectations should be validated in the corpus results from Yucatec Maya presented in Table 7. The row on the left presents a query in the first 20 sentences of 10 narrative texts. The row on the right presents a query of the occurrences of the following 14 transitive verbs in a sample of 20 narrative texts (approx. 2,500 clauses) ${ }^{13}$ : kiims 'kill', pakt 'look at, gaze', kaxant 'seek, persecute', hats' 'beat', cha'nt 'contemplate', t'àan(t) 'call', xíimbat 'visit', $u$ 'y 'hear', ts'on 'shoot', mach 'seize', ch'ak 'cut', hàant 'eat', áant 'help', kanáant 'guard'. Note that we excluded the following tokens in Table 7: one argument was a complement clause, or the verb appeared in a passive, reflexive, or imperative form, or in a collocation.

\begin{tabular}{|l|l|cc|cc|}
\hline & & \multicolumn{2}{|c|}{ random text measurement } & \multicolumn{2}{c|}{ transitive verbs in corpus } \\
\hline arguments & order & n of occurrences & $\%$ & n of occurrences & $\%$ \\
\hline 0 & $\mathrm{~V}$ & 50 & 28,9 & 50 & 38,1 \\
\hline 1 & $\mathrm{VA}$ & 12 & 6,9 & 8 & 6,1 \\
& $\mathrm{~A}_{\mathrm{TOP}} \mathrm{V}$ & 10 & 5,7 & 3 & 2,2 \\
& $\mathrm{VP}$ & 84 & 48,5 & 50 & 38,1 \\
& $\mathrm{P}_{\mathrm{FOC}} \mathrm{V}$ & 7 & 4 & 3 & 2,2 \\
\hline \multirow{2}{*}{2} & $\mathrm{VPA}$ & 1 & 0,5 & 2 & 1,5 \\
& $\mathrm{VAP}$ & 1 & 0,5 & 0 & 0 \\
& $\mathrm{~A}_{\mathrm{TOP}} \mathrm{VP}$ & 7 & 4 & 12 & 9,1 \\
& $\mathrm{P}_{\mathrm{FOC}} \mathrm{VA}$ & 1 & 0,5 & 2 & 1,5 \\
& $\mathrm{~A}_{\mathrm{TOP}} \mathrm{P}_{\mathrm{FOC}} \mathrm{V}$ & 0 & 0 & 1 & 0,7 \\
\hline & sum & $173^{14}$ & 99,5 & 131 & 99,5 \\
\hline
\end{tabular}

Table 7: Argument orders in naturalistic data

The corpus results in Table 7 support the above expectations. Transitive clauses with two overtly realized arguments are the minority of tokens in spontaneously produced data. When only one argument is realized, the postverbal order is preferred to the preverbal one. Overt patients occur more frequently than overt agents, since agents are frequent discourse topics. When two arguments occur however, the situation is different: the orders with postverbal arguments are then very rare; instead, the most frequent order is the topic-comment structure $\mathrm{A}_{\mathrm{TOP}} \mathrm{VP}$. The four instances of sentences with two postverbal arguments in our corpus show variation between VPA and VAP ( 3 and 1 occurrences respectively). The varying order in the spontaneous data fits with the results from our comprehension experiment.

13 The texts are part of a corpus which has been compiled and elaborated in diverse linguistic projects under the leadership of Christian LeHManN.

14 Note that only occurrences of transitive verbs are counted so that the total number of verbs is not identical to the number of sentences investigated. 


\section{Synthesis}

The comprehension experiment in interpreting ambiguous sentences with two postverbal lexical NPs in Yucatec Maya shows that the order in the postverbal domain of this language varies to a great extent. This result contrasts with previous analyses based on simple elicitation which assume a basic VPA order for this language. In our results, 10 speakers from a small and linguistically uniform Yucatec speaking community have shown highly divergent preferences, including a flexible VPA and a flexible VAP group, a rigid VPA speaker, and a group that fundamentally disfavored two postverbal lexical arguments. On the basis of these results, we assume constraint instability in the postverbal argument orders in Yucatec Maya.

Seeking an explanation, we have shown on the basis of corpus data that sentences with two postverbal arguments are very rare in narrative texts. This is due to the general tendency to produce transitive clauses in a topic-comment structure in spontaneous discourse. Given that Yucatec Maya, as many other verb initial languages, displays different orders for topic-comment and for pragmatically neutral sentences, the pragmatically neutral order is expected to occur rarely, and this expectation has been verified in the corpus. In this sense, the combination of verb first and head-marking with a flexible word order is an expected grammar: in the rare occurrences of two postverbal arguments pragmatics suffice to eliminate resulting ambiguities.

Our comprehension experiment manipulated the variables of animacy, definiteness and verbal aspect in ambiguous sentences. The results show that speakers with flexible orders are considerably influenced by animacy in their preferences for role choice. Speakers of both groups (flexible VAP and flexible VPA) changed their ordering preferences in order to avoid an inverse alignment, in which the lower animate acts upon the higher one. The effects of definiteness on word order are less clear compared to the results of animacy. A general tendency for harmonic alignment (agent/definite, patient/indefinite) is again apparent, but its quantitative effect is less salient than the effect of direct alignment in animacy. A last hypothesis, which has been proven false, was that verbal aspect has an impact on word order. Our results have shown that speakers interpreted the stimuli quite uniformly in both aspects (completive, incompletive).

In addition, our results provide evidence for a constraint penalizing ambiguous constructions as has already been argued for Yucatec Maya and other Mayan languages. Sentences with two NPs that differ either in animacy or in definiteness were interpreted with less difficulty than sentences with NPs with equivalent properties.

Lastly, a data set was devoted to inspect the conflict between pragmatic preferences and the harmonic alignment of animacy and thematic role. The experimental sentences were of the type "lower animate acts upon higher animate" and were pragmatically interpreted by all speakers violating word order preferences and animacy/role alignment preferences whenever necessary. These results imply a scalar correlation between the identifiability of two postverbal NPs and the degree of pragmatic certainty for the role choice. In this sense, the conditions tested are arranged in the following hierarchy:

$$
\begin{aligned}
& \text { clauses with pragmatically favorite roles }> \\
& \text { asymmetric clauses (human, non-human) }> \\
& \text { symmetric clauses (either } 2 \text { humans or } 2 \text { non-humans). }
\end{aligned}
$$

A peculiar result of our experiment was the high index of " 1 argument" interpretations: 8 out of 10 speakers gave $29.4 \%$ " 1 argument" interpretations and another two speakers 
only gave this kind of interpretation. During the validation of our hypotheses, we used the rise of this index as a form of negative evidence for the optimality of our experimental conditions. However, it remains in question which factor positively triggers the high preference for control in Yucatec Maya. A possible explanation may stem in the processing peculiarities of verb-initial sentences and the general preference to bind anaphoric elements on the left. This should be seen in the view of a head-marking language, where the verb is a potential clause (see section 2.2). In "1 argument" interpretations, speakers bind the cross-reference markers on the left as soon as they are introduced. Given that the agent of the matrix clause controls the agent person affix of the subordinate verb, the postverbal NPs are processed as patients.

\begin{tabular}{llll}
\multicolumn{2}{l}{ Abbreviations } & \\
A & set-A person marker & IPFV & imperfective \\
AG.NR & agent nominalizer & LOC & locative \\
B & set-B person marker & M & masculine \\
CL.AN & class for animates & PFV & perfective \\
CMPL & completive & PL & plural \\
DEF & definite & QUOT & quotative \\
Dn & deictic,person $n$ & SG & singular \\
(e.g. D2 & deictic,2.person) & SR & subordinator \\
F & feminine & TOP & topic \\
FUT & future & TRR & transitivizer \\
INCMPL & incompletive & &
\end{tabular}

\section{Text sources}

Hapaikan Dzul Poot, Domingo (1985): Hapai kan, in: Cuentos mayas. Edición bilingüe: español maya. Mérida, Yucatán: Maldonado; INAH, SEP; 55-58.

Hk'an Dzul Poot, Domingo (1986): J-k'an yajaw, in: Cuentos mayas; tomo II; edición bilingüe: español-maya. Mérida, Yucatán: Maldonado; INAH, SEP; 89-114.

\section{References}

Aissen, Judith (1987): Tzotzil clause structure. Dordrecht: Reidel.

Aissen, Judith (1992): Topic and focus in Mayan, in: Language 68, 43-80.

Aissen, Judith (1997): On the syntax of obviation, in: Language 73(4), 705-750.

Aissen, Judith (1999): Markedness and subject choice in optimality theory, in: Natural language and linguistic theory $17,673-711$.

Ayres, Glenn (1983): The antipassive "voice" in Ixil, in: International Journal of American Linguistics 49(1), 20-45.

Bock, J. K.; Loebell, H. \& Morey, R. (1992): From conceptual roles to structural relations: Bridging the syntactic cleft, in: Psychological Review 99, 150-171.

BOHNEMEYER, JÜRGEN (1998a): Time relations in discourse: Evidence from a comparative approach to Yukatek Maya. Ph. D. Dissertation, Katholieke Universiteit Brabant.

Bohnemeyer, Jürgen (1998b): Sententiale Topics im Yukatekischen, in: Zaefferer, Dietmar (ed.), Deskriptive Grammatik und allgemeiner Sprachvergleich. Tübingen: Niemeyer, 55-85.

BoHNEMEYER, JÜrGEN (2004): Split intransitivity, linking, and lexical representation: the case of Yukatek Maya, in Linguistics 42, 67-107.

Bricker, Victoria R. (1979): Wh-questions, relativization, and clefting in Yucatec Maya, in: Martin, LAURA (ed.), Papers in Mayan linguistics. Columbia, Miss.: Lucas Brothers, 107-136.

Broadwell, George Aaron (2000): Word order and markedness in Kaqchikel, in: Butt, Miriam \& King, Tracy Holloway (eds.), Proceedings of the LFG00 Conference. Stanford: CSLI Publications. 
Broadwell, George Aaron (i.p.): Valence, transitivity, and passive constructions in Kaqchikel, in: Kulikov, Leonid; de Swart, Peter \& Malchukov, Andrej (eds.), Case, valency, and transitivity. Amsterdam: Benjamins.

BRody, M. JILL (1982): Discourse processes of highlighting in Tojolabal morphosyntax. Ph.D. dissertation, Washington Univ.

Clark, Herbert H. \& Clark, Eve V. (1977): Psychology and language. New York: Harcourt Brace Jovanovich.

Clark, Herbert H. \& Haviland, S. (1977): Comprehension and the given-new contrast, in: Freedle, Roy O. (ed.), Discourse production and comprehension. Hillsdale, NJ: Erlbaum, 1-40.

Cristofaro, Sonia (2003): Subordination. Oxford: Oxford University Press.

CROFT, William (2001): Radical construction grammar: syntactic theory in typological perspective. Oxford: Oxford University Press.

DANZIGER, Eve (1996): Split intransitivity and active-inactive patterning in Mopan Maya, in: International Journal of American Linguistics 62,379-414.

DAYLEy, Jon P. (1985): Tzutujil Grammar. (UCPL 107). Berkeley \& Los Angeles: University of California, Berkeley.

Dixon, Robert M. W. (1979): Ergativity, in: Language 55, 59-138.

DowTY, DAVID (1991):Thematic Proto-roles and argument selection, in: Language 67, 547-619.

Dryer, Matthew (1997): Are grammatical relations universal?, in: Bybee, JoAn et al. (eds.), Essays on language function and language type: dedicated to T. Givón. Amsterdam etc.: Benjamins, 115-143.

Du Bois, John W.; Kumpf, Lorraine E. \& Ashby, William J. (eds.) (2003): Preferred argument structure: Grammar as architecture for function. Amsterdam/Philadelphia: Benjamins.

Duncan, Lachlan (2003): The syntactic structure of Tz'utujil Maya, in: Butt, Miriam \& King, Tracy Holloway (eds.), Proceedings of the LFG03 Conference. Stanford: CSLI Publications, 164-183

Durbin, Marshall \& OJeda, Fernando (1978): Basic word-order in Yucatec Maya, in: England, Nora C. (ed.), Papers in Mayan Linguistics. Vol. 2. (University of Missouri Miscellaneous Publications in anthropology 6). Columbia: University of Missouri, Department of Anthropology, 69-77.

England, Nora C. (1989): Comparing Mam (Mayan) clause structures, in: International Journal of American Linguistics 55(3), 283-308.

EngLAND, NoRA C. (1991): Changes in basic word order in Mayan languages, in: International Journal of American Linguistics 57(4), 446-486.

England, Nora C. \& Martin, Laura (2003): Issues in the comparative argument structure analysis in Mayan narratives, in: Du Bois, John W.; Kumpf, Lorraine E. \& Ashby, William J. (eds.), Preferred argument structure: Grammar as architecture for function. Amsterdam/Philadelphia: Benjamins, $131-157$.

FAnSelow, Gisbert (2002): Quirky subjects and other specifiers, in: Kaufmann, B. \& Stiebels, B. (eds.), More than words. Berlin: Akademie Verlag, 227-250.

Foster, Joseph F. \& Hofling, Charles A. (1987): Word order, case, and agreement, in: Linguistics 25, 475-499.

Givón, TALmy (1980): The binding hierarchy and the typology of complements, in: Studies in Language 4, 333-378.

Grinevald Craig, Colette (1977): The structure of Jacaltec. Austin \& London: University of Texas Press.

Hofling, Charles Andrew (1984): On proto-Yucatecan word order, in: Journal of Mayan Linguistics $4(2), 35-64$.

Hofling, Charles Andrew (2003): Tracking the deer: Nominal reference, parallelism and preferred argument structure in Itzaj Maya narrative genres, in: Du Bois, John W.; KumpF, Lorraine E. \& Ashby, William J. (eds.), Preferred argument structure: Grammar as architecture for function. Amsterdam/Philadelphia: Benjamins, 385-410.

Keenan, Edward (1976): Remarkable subjects in Malagasy, in: Li, Charles (ed.), Subject and topic. New York etc.: Academic Press, 247-301.

KeEnan, Edward (1978): The syntax of subject-final languages, in: Lehmann, Winfred P. (ed.), Syntactic typology. Austin: University of Texas Press, 267-327.

LEHMANN, CHRISTIAN (1991): Yukatekisch, in: Zeitschrift für Sprachwissenschaft 9(1/2), 28-51.

Lehmann, Christian (1998): Possession in Yucatec Maya. (LINCOM Studies in Native American Linguistics 4). Unterschleissheim: LINCOM Europa.

Mondloch, James L. (1981): Voice in Quiché Maya. Ph.D. dissertation, State University of New York, Albany. 
Nichols, Johanna (1986): Head-marking and dependent-marking grammar, in: Language 62(1), 56-119.

Norman, William N. \& Campbell, Lyle (1978): Toward a Proto-Mayan syntax: a comparative perspective on grammar, in: England, Nora C. (ed.), Papers in Mayan Linguistics. Vol. 2. (University of Missouri Miscellaneous Publications in anthropology 6). Columbia: University of Missouri, Department of Anthropology, 136-155.

PeArson, MAtThew (2001): The clause structure in Malagasy: a minimalist approach. Ph. D. dissertation, UCLA.

Peñalosa, Fernando (1987): Major syntactic structures of Acatec (Dialect of San Miguel Acatán), in: International Journal of American Linguistics 53(3), 281-310.

Quizar, Stephanie (1979): Comparative word order in Mayan. Ph. D. dissertation, University of Colorado, Boulder.

Robinson, StUART (2002): Constituent order in Tenejapa Tzeltal, in: International Journal of American Linguistics 68.1, 51-80.

Santos Nicolas, Jose Francisco et al. (1997): Gramatica del idioma Pocomam. Proyecto Lingüístico Francisco Marroquin, La Antigua Guatemala.

Steele, Susan (1978): Word order variation: a typological study, in: Greenberg, Joseph (ed.), Universals of human language, vol. 4. Stanford: Stanford University Press, 585-623.

Tonhauser, Judith (2003): F-constructions in Yucatec Maya, in: Anderssen, Jan; Menéndez-Benito, Paula \& Werle, Adam (eds.), The Proceedings of SULA 2. Vancouver, BC: GLSA, University of Massachusetts, Amherst.

Trechsel, Frank R. (1993): Quiché focus constructions, in: Lingua 91,33-78.

Tzul, Julio Alberto \& Tzimaj Cacao, Alfonso (1997): Gramatica del idioma Q'eqchi'. Proyecto Lingüístico Francisco Marroquin, La Antigua Guatemala.

VAN VALin, RoBert D. (1987): The role of government in the grammar of head-marking languages, in: International Journal of American Linguistics 53(4), 371-397.

Van Valin, Robert D. \& LaPolla, Randy J. (1997): Syntax: Structure, meaning and function. Cambridge etc.: Cambridge University Press.

Verhoeven, Elisabeth (2005): Experiential constructions in Yucatec Maya. A typologically based analysis of a functional domain in a Mayan language. $\mathrm{Ph}$. D. dissertation, University of Erfurt.

Zavala, Roberto (1997): Functional analysis of Akatek voice constructions, in: International Journal of American Linguistics 63(4), 439-474.

Stavros SKopeteas

SFB 632

Institut für Linguistik

Universität Potsdam

Postfach 601553

D-14415 Potsdam

GERMANY

skopetea@rz.uni-potsdam.de
Elisabeth Verhoeven

Fachbereich 10

Sprach- und Literaturwissenschaften

Universität Bremen

Postfach 330440

D-28334 Bremen

GERMANY

everhoev@uni-bremen.de 